\title{
Wave approach for modeling pressure swing adsorption
}

\author{
M.B. Kravchenko, Doctor of Technical Sciences. \\ Odessa National Academy of Food Technology, Kanatnaya str. 112, Odessa, Ukraine, 65039. \\ E-mail: kravtchenko@i.ua.
}

A new approach to modeling of the pressure swing adsorption (PSA) based on a wave method for calculating nonstationary periodic mass transfer processes is proposed. The analysis of solutions for plants designed to produce oxygen from air is given. The conditions necessary for highly efficient operation of PSA plants are formulated. The results of calculations for various brands of zeolites are followed, allowing optimizing a choice of zeolite for the set working conditions.

Key words: Pressure swing adsorption, Adsorption, Zeolite, Oxygen, Nitrogen.

\section{Хвильовий підхід до моделювання короткоциклової безнагрівної адсорбції}

Запропоновано новий підхід до моделювання короткоичклової безнагрівної адсорбиії (КБА) на основі хвильового методу для обчислення нестаціонарних періодичних процесів масо-переносу. Наведений аналіз рішень для установок, які призначені для отримання кисню з повітря. Сформульовані умови високоефективної роботи установок КБА. Наведені результати розрахунків для різних марок цеолітів, які дозволяють оптимізувати вибір иеоліту для заданих умов роботи.

Ключові слова: Короткочиклова безнагрівна адсорбиія, Адсорбція, Цеоліт, Кисень, Азот.

(C) The Author(s) 2018. This article is an open access publication

This work is licensed under the Creative Commons Attribution 4.0 International License (CC BY) http://creativecommons.org/licenses/by/4.0/

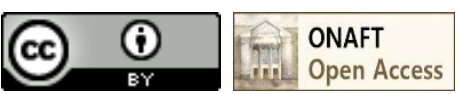

\section{INTRODUCTION}

A numerous plants, operating on the principle of pressure swing adsorption (PSA), are present on the market today. These plants allow the purification and enrichment of various technical gases, for example, such as nitrogen, oxygen, methane, hydrogen, and others.

The principle of operation of all modern pressure swing adsorption installations is analogous to the principle of operation of the apparatus for separating gas mixtures by adsorption, patented in 1960 by the American inventor Scarstrom [1]. Figure 1 shows the scheme and the cycle diagram of the Scarstrom installation.

The main idea of Scarstrom is that the part of production gas expands to barometric pressure, and is used to regenerate the adsorbent. After expansion of a part of production gas, intended for the regeneration of adsorbent, its volume is greater than the volume of the compressed gas entering the unit. Therefore, the partial pressure of impurity, from which the gas is purified, becomes substantially smaller than the partial pressure of this impurity in the incoming gas. Due to this, the almost complete regeneration of the adsorbent is achieved.

Modern installations, working on the principle of pressure swing adsorption, make it possible to obtain products of high purity. So, for example, in the units for oxygen production from air, it is possible to obtain oxygen with a purity of more than $90 \%$ and at the same time have an extraction ratio of about $40 \%[3,4,5,6]$.

It is customary to assume that the operation of PSA units for production of the oxygen is based only on the difference in the adsorption of various air components $[2,3,4,5]$. So, for example, synthetic zeolite grade $\mathrm{CaX}$ (analogue of zeolite 5a), which can be used in plants for production of oxygen by the PSA method [3, 7, 8], actually absorbs nitrogen about three to five times more active than oxygen. But, strictly speaking, this does not mean that the operation of the PSA installations is based on this difference. In fact, this hypothesis has never been questioned, since it is considered quite obvious.

To understand the essence of the problem, considered in this paper, let's conduct a simple thought experiment.

We take $1 \mathrm{~m}^{3}$ of air at the absolute pressure of 6 bars and let it pass through a layer of ideally regenerated zeolite of the brand $\mathrm{CaX}$, absorbing nitrogen about five times more active than oxygen. The equations of adsorption isotherms of oxygen and nitrogen for the given zeolite are taken from the review [4].

Graphs of changes in the partial pressures of oxygen and nitrogen as the gas moves in the layer of zeolite are shown in Figure 2. As can be seen from these graphs, the partial pressure of nitrogen actually falls faster than the partial pressure of oxygen, but nitrogen in the air is about four times larger than oxygen. 


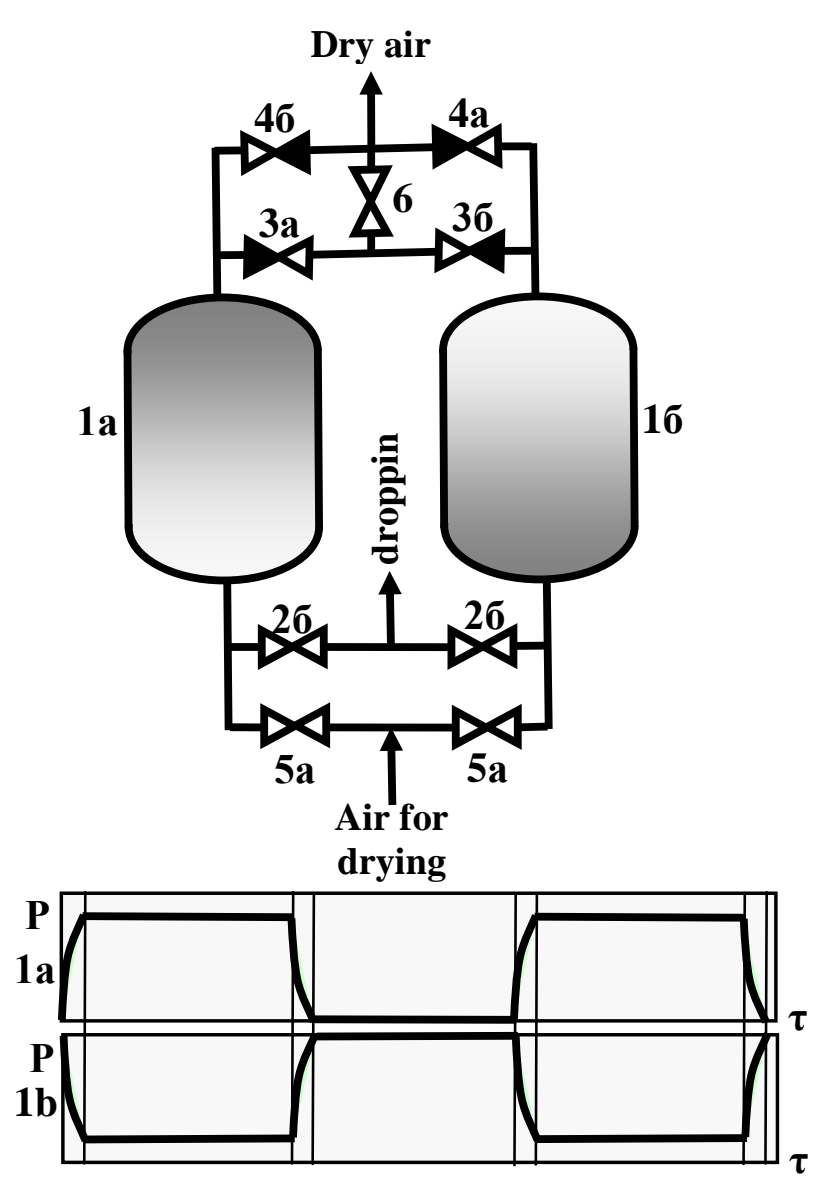

Figure 1. Schematic diagram and cyclogram of operation of the Scarstrom patent air drying unit. 1 - adsorber; 2,5 - solenoid valves; 3,4- check valves; 6 - throttle;

$\mathrm{P}$ is the pressure; $\tau$ is the time

Therefore, the intersection of partial pressure plots for

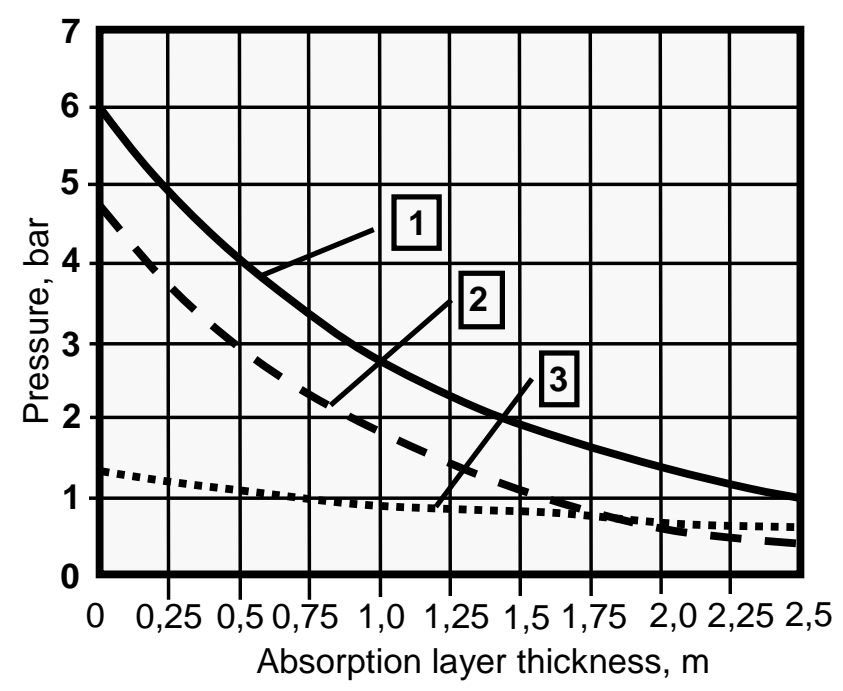

Figure 2. Absorption of nitrogen and oxygen in the layer of the brand $\mathrm{CaX}$ zeolite.

1 is the total pressure of the mixture;

2 is the partial pressure of nitrogen;

3 is the partial pressure of oxygen. oxygen and nitrogen, corresponding to a 50\% oxygen concentration, is achieved only at absolute air pressure of about 1.75 bar. In other words, to achieve an oxygen concentration of $50 \%$, the adsorbent must absorb about $75 \%$ of the original air. The maximum oxygen concentration that can be obtained at the outlet of such adsorber at the pressure of 1 bar is approximately $60 \%$. But in this case the oxygen recovery ratio from the air will be close to zero.

Moreover, regeneration of the adsorbent with a gas with nitrogen concentration close to $50 \%$, does not allow completely regenerate this adsorbent, therefore in the next cycle the partial pressure of nitrogen at the outlet from adsorber will be even higher. Consequently, the production of oxygen with a concentration of more than $50 \%$ only due to the difference in the adsorption of oxygen and nitrogen by the zeolite of $\mathrm{CaX}$ is very problematic.

This simple example clearly shows that an only difference between adsorption from oxygen and nitrogen is not sufficient to produce $90 \%$ oxygen with a recovery ratio of about $40 \%$.

Firms producing equipment with such high technical characteristics are in no hurry to share methods of calculation and experience in developing such installations with potential competitors. Therefore, they publish only promotional materials, which contain a minimum of technical details about the work of the plants they produce.

On the other hand, dozens of scientific publications exist in the open access, which describe, in fact, the same mathematical model of pressure swing adsorption, built using the diffusion equation in a moving gas component [9, $10,11,12]$.

None of these publications mention any effects, due to which it is possible to achieve such high technical parameters as are available in the best examples of industrial installations. Nevertheless, this does not prevent authors of publications from declaring good agreement between the calculating results and available experimental data.

In this paper, an attempt has been made to construct a mathematical model of PSA for obtaining oxygen from air, based on the previously proposed theory of wave adsorption. This approach allows us to explain the effects that make it possible to achieve such high technical indicators as are available in modern PSA installations. In addition, the proposed mathematical model makes it possible to clarify the requirements for adsorbents that are necessary for the efficient operation of PSA installations.

\section{CONSTRUCTION OF A MATHEMATICAL MODEL OF PSA}

For an analytical description of the kinetics and dynamics of adsorption, let us use the model of wave adsorption given in $[13,14]$. This model makes it possible to calculate nonstationary adsorption processes with a variable composition of a gas at the inlet to the adsorption apparatus.

In the mathematical description of the process of a gas mixture adsorption, as in [13], the following pattern of component propagation in a porous layer of an adsorbent is adopted.

The component of interest to us will be considered dissolved in an unadsorbed carrier gas, which is filtered at a 
constant rate through the adsorbent bed. The use of a carrier gas in the mathematical model is equivalent to accepting the assumption that there is no longitudinal mixing of a gas moving in the adsorber. In addition, the carrier gas, which moves at a constant speed, is using as a moving reference frame, relative to which the phase shift of the concentration of the absorbed component is determined. Therefore, the carrier gas is an abstract element in the mathematical model under consideration and its presence is not necessary for the physical realization of this model.

Near the contact points of the adsorbent grains, are formed stagnation zones, where the gas is practically stationary. The main flow of the carrier gas with the dissolved component passes through a chain of cavities and voids in the space between the grains of the adsorbent. Thus, the entire space in which the adsorbent is located is mentally be split into two parts: a fixed frame of adsorbent grains with adjoining stagnant zones, and a system of interconnected voids and channels in which the carrier gas with the dissolved component moves.

In the fixed frame, the propagation of the component which we are interested is basically due to molecular diffusion in the carrier gas.

In the system of channels located between the adsorbent grains the component is transferred mainly due to convection.

In the proposed formulation of problem, transfer of the component of interest to us from the fixed frame to the moving carrier gas is considered as a drain of this component in the problem of molecular diffusion of a component in a stationary framework. Convection of the same component in channels with a moving carrier gas is described by a separate equation of the material balance of the component.

Taking into account the above, the molecular diffusion equation in a fixed frame can be written in the form:

$$
\begin{aligned}
& D_{E} \frac{\partial^{2} C(x, y, \tau)}{\partial x^{2}}+D_{E} \frac{\partial^{2} C(x, y, \tau)}{\partial y^{2}}- \\
& -\beta \cdot F[C(x, y, \tau)-C g(x, \tau)]= \\
& =\left(\frac{d a}{d C}\right) \frac{\partial C(x, y, \tau)}{\partial \tau},
\end{aligned}
$$

where $C(x, y, \tau)$ is the current molar concentration of the component in the fixed frame (gas located in the adsorbent pores and stagnant zones, around the adsorbent particles), $\left[\mathrm{m}^{3} / \mathrm{m}^{3}\right]$;

$C g(x, \tau)$ is the current molar concentration of the component in question in a moving carrier gas, $\left[\mathrm{m}^{3} / \mathrm{m}^{3}\right]$;

$\beta$ is the mass transfer coefficient between the gas of the fixed frame and the gas moving in the cavities between the grains of the adsorbent, $\left[\mathrm{m}^{3} /\left(\mathrm{s} \cdot \mathrm{m}^{2}\right)\right]$;

$F$ is the specific contact surface of the fixed frame and the moving carrier gas, $\left[\mathrm{m}^{2} / \mathrm{m}^{3}\right]$;

$D_{E}$ is the equivalent value of the sorbate diffusion coefficient in the grain of the adsorbent, taking into account the diffusion features in the porous body - the relative pore volume, the variable pore cross section, the presence of dead-end pores, etc., $\left[\mathrm{m}^{2} / \mathrm{s}\right]$.

$$
\left(\frac{d a}{d C}\right)=K_{G} \text { is the dimensionless form of the Henry }
$$

constant for the component absorbed by the adsorbent, where $a$ is the adsorption of gas, expressed in cubic meters of sorbate per $1 \mathrm{~m}^{3}$ of bulk volume of the adsorbent.

In the recorded diffusion equation of a component in a fixed frame, the Henry constant is present. This means that in the proposed mathematical model, a linear model of adsorption of gas by an adsorbent is adopted. The adsorption isotherm corresponding to this model is known as the Henry isotherm.

The material balance of the component in question in the elementary volume of the carrier gas moving along the system of cavities between the grains of the adsorbent can be written in the form of a one-dimensional differential equation:

$$
\begin{aligned}
& \beta \cdot F[C(x, \delta, \tau)-C g(x, \tau)]= \\
& =G \cdot \frac{d C g(x, \tau)}{d x} ;
\end{aligned}
$$

where $G$ is the molar flow rate of the carrier gas mixture with the dissolved component, referred to the unit cross-section of the adsorbent bed, $\left[\mathrm{m}^{3} / \mathrm{s}\right]$. [m].

$\delta$ is the characteristic grain size in the adsorbent bed,

These two equations, when combined, allow us to find the distribution of the concentration of the component in a moving carrier gas and in a fixed frame.

Since the specific surface of the immovable frame is used in the mathematical model, which can be assumed to be equal to the surface of the adsorbent grains per unit volume of the adsorbent $F$, then together with the characteristic grain size of the adsorbent $\delta$, this makes it possible to accurately take into account the shape and sizes of the adsorbent grains used.

In this paper we consider the steady-state periodic adsorption process. Therefore, the gas flow at the inlet to each adsorber of the PSA unit can be represented as an infinite periodically repeating concentration signal. It is known from mathematical analysis that any periodic signal can be represented as the sum of an infinite series of harmonic oscillations. Therefore, knowing the shape of the concentration signal entering the adsorber, it is possible to expand it into a Fourier series in the natural frequencies of a given adsorption apparatus. These frequencies of the concentration waves are called the eigenfrequencies of the adsorption apparatus, because a whole number of waves fit along the adsorber length.

In the author's paper [14], the analytical solution of the system of equations (1) and (2) is given for any eigenfrequencie concentration wave. This solution is the wave with the same frequency and amplitude, but lagging behind the phase from the wave at the entrance to the adsorber (see Figure 3). Moreover, this lag depends both on the parameters of the adsorber, and on the frequency of the incoming wave. Therefore, at the exit from the adsorber, the shape of the periodic concentration signal is blurred.

Since the amplitude of each natural wave at the input and output is the same, the material balance of the adsorber is automatically satisfied.

The sum of the analytical solutions obtained for individual concentration waves at the exit from the adsorber 
gives an analytical solution to the problem of passing a periodic concentration signal of arbitrary shape through an adsorber. An example of solving the problem of passing a periodic concentration signal through an adsorbent layer is considered in the author's paper [14].

But to build a mathematical model of a PSA installation this is not enough, since the gas flow in the adsorber of the PSA unit moves alternately, first in one direction and then in the other. This problem can be solved by using the linearity of the system of equations (1) and (2).

As is known, if there are two particular solutions of a system of linear homogeneous differential equations, then the sum or difference of these solutions will also be a solution of this system of differential equations. Therefore, in order to build a mathematical model of the PSA installation, it is possible to combine the solution for the direct flow of to be separated mixture with the solution for the regenerating gas flow moving in the opposite direction.

Since the sum and difference of the solutions of the problem for the direct flow of the separated mixture and the problem for the regenerating gas flow are mathematically equivalent, this means that the system of differential equations (1) and (2) with alternating motion of the gas, have two solutions. Which of these solutions will be implemented is determined by the initial conditions.

The PSA installation is a complex self-oscillating system with nonstationary processes and flows. Therefore, the modelling and calculations of such installations should be carried out on the basis of the conceptual apparatus and methods of the theory of dynamical systems.

In terms of the dynamical systems theory, the steadystate operating mode of a PSA installation with repeated oscillations of concentrations and pressures of components is usually called the limit cycle. The different starting modes of PSA installation in which the concentrations and pressures of the components of the mixture to be separated do not repeat, in the limit, lead to the same steady-state operating mode of the plant - to its limit cycle.

In the dynamical systems theory, objects with several limit cycles are also known. The initial conditions under which the system can go to several limit cycles are called bifurcation points.

Consequently, the adsorber of the PSA installation through which alternately passes the carrier gas with the adsorbed component and the counter flow of the regenerating gas has two steady-state operating modes or two limit cycles in the terminology of the theory of dynamical systems.

One limit cycle is achieved when the PSA unit is started with the completely regenerated adsorbent. In this case, when a carrier gas mixture with the absorbed component passes through the adsorber, the component will be actively absorbed and an almost pure carrier gas will leave the adsorber. The regenerating gas, which in this case is a practically pure carrier gas, will wash out the absorbed component from the adsorber. As a result, the absorbed component will practically not pass through the PSA installation.

The second stable operation mode of the PSA installation will be realized if, before starting the installation, the adsorbent will saturated with the absorbed component. In this case, as the carrier gas and adsorbed component passes through the adsorbent bed, the component will not be absorbed by the adsorbent, since it is already saturated with this component. Therefore, a gas will leave the PSA unit with very nearly the same content of the component as in the input of this installation. If such gas will used to regenerate the adsorbent, the content of the component in the adsorbent will also remain unchanged. Consequently, in this mode, the absorbed component, on the contrary, will easily pass through the PSA installation.

It should be noted that both described operating modes can be implemented on the same installation with the same adsorbent. The transition from one stable state to another will occur when at the moment of starting the plant a certain degree of saturation of the adsorbent is reached. This degree of saturation of the adsorbent with the absorbed component, in terms of the theory of dynamical systems, will be a bifurcation point from which, as a result of negligible deviations, any of the two operating modes of the system can be achieved.

If we consider atmospheric air as a mixture of two components: nitrogen and oxygen, then for the simulation of a PSA unit intended, for example, to obtain oxygen, it is necessary to separately consider absorption processes of oxygen and nitrogen. In this case there will be not two but four initial conditions.

The first mode, the easiest from the point of view of analysis, when starting the installation the adsorbent is completely regenerated both for oxygen and nitrogen. This case is discussed in detail in the introduction to the article. In this mode, the oxygen concentration at the outlet of the plant is determined by the difference in the adsorption of the components of the mixture supplied to the inlet of the adsorber. If, for example, nitrogen is absorbed several times more active than oxygen, then at the outlet of the unit, air enriched with oxygen to a concentration of $50-60 \%$ will be obtained.

Perhaps it was in this mode the pilot installation of the PSA, created in the USSR in 1980 and described in the review [4], was working. The installation produced approximately $5 \mathrm{~m}^{3} / \mathrm{h}$ of air enriched with oxygen to the concentration of $50 \%$. Such a low concentration of oxygen can be explained by the fact that the installation was created in accordance with the ideas that are available in the open access.

This, and not the low selectivity of the adsorbents used, apparently explains the low efficiency of the first PSA plants for producing oxygen [2].

The second possible operating mode of the PSA plant is, when the unit starts working with the adsorbent completely saturated with nitrogen and oxygen. In this case, the oxygen concentration at the outlet of the adsorbent bed, as in the previous case, will be determined by the difference in adsorption of separated components of mixture. It is not difficult to see that in the first and second operating mode of the PSA installations, an equally low oxygen concentration will be obtained $-50-60 \%$. Therefore, both considered cases are of no practical interest.

The third operating mode of the BKA installation is obtained when, when switched on, the adsorbent is saturated with oxygen and regenerated for nitrogen. In this case, from the air entering the adsorber, nitrogen will be actively absorbed, but practically all of the oxygen will pass through the adsorber. As a result, practically pure oxygen will leave the adsorber. If part of this gas is sent to 
regenerate the adsorbent, even after it is expanded to near atmospheric pressure, the oxygen partial pressure in the regenerating gas will also be quite high. If, for example, the pressure of the incoming air is 5 bar, then the partial pressure of oxygen in such air will be approximately 1 bar. Therefore, during the operation of the unit, degree of the adsorbent oxygen saturation will be little changing. Consequently, the almost complete saturation of the adsorbent with oxygen during the operation of the PSA is a necessary condition for achieving high values of the oxygen recovery factor.

A completely different picture holds for nitrogen. Since the regenerating gas contains little nitrogen, the adsorbed nitrogen will effectively be carried away from the adsorbent by the regenerating gas.

Obviously, in this operating mode of the PSA unit it is possible to obtain practically pure oxygen in a relatively large amount.

If during the shutdown of the installation, its adsorbers are filled with oxygen, then after the start-up, such an installation very quickly enters the regime of obtaining practically pure oxygen.

And, finally, the fourth case, when the PSA unit starts working with the adsorbent saturated with nitrogen and regenerated for oxygen. In the same way as it was shown in the previous case, it can be concluded that at the output of such an installation there will be practically pure nitrogen. And for this it is not necessary at all that the absorption of oxygen by the adsorbent used in the installation is greater than the adsorption of nitrogen.

In modern installations for obtaining nitrogen from the air using pressure swing adsorption technology, activated carbon is usually used as an adsorbent, despite the fact that activated carbon, in a statics, adsorbs nitrogen better than oxygen. It is believed that air separation in this case occurs due to differences in the kinetics of oxygen and nitrogen adsorption on activated carbon. Indeed, if the duration of the adsorption process less than one minute, oxygen is absorbed by activated carbon about ten times faster than nitrogen. But by calculation similar to that given in the introduction, it is not difficult to show that this is not enough to obtain nitrogen purity of $99.9 \%$ or more.

Therefore, to obtain a high concentration of air separation products, it is not necessary to have an adsorbent with a large difference in the statics of adsorption of oxygen and nitrogen. This difference in adsorption is necessary only to bring the installation to the required operating mode.

If the Henry constant for nitrogen adsorption is much larger than the Henry constant for oxygen adsorption, the bifurcation point will be below $21 \%$ of oxygen. In this case, when compressed air is supplied to the PSA input at its outlet, the oxygen concentration will increase after each cycle until it reaches the limit cycle or steady-state operation of the unit with a high oxygen concentration at the outlet.

Likewise, for PSA plants designed to produce nitrogen, a high oxygen absorption rate makes it possible to enter a regime with a high nitrogen concentration, despite the fact that in the static, activated carbon adsorbs nitrogen better than oxygen.

It remains to answer the question of, why argon in the separation of air using the PSA technology is practically all comes together with oxygen, despite the fact that the adsorbent is not specially saturated or regenerated by argon.

This is explained by the fact that argon is adsorbed on the same active centers of the adsorbent surface that oxygen and, therefore, competes with oxygen for this active sites. As a consequence, when adsorbent is saturated with oxygen the adsorption of argon by this adsorbent decreases. In other words, saturation of the adsorbent with oxygen is equivalent to its saturation with argon. Therefore, if oxygen passes through the adsorber almost unobstructed, then argon will easily pass through the same adsorber, and, conversely, if the adsorber absorbs oxygen, it will also actively absorb argon.

It follows that the necessary condition for the efficient operation of the PSA unit is the adsorption of the components of the mixture at various active centers on the surface of the adsorbent. An external manifestation of this is the independence of adsorption of one component from the degree of saturation with other components of the mixture. In fact, it is during the adsorption of molecules of separated gases at various active centers of the adsorbent surface that a gas mixture is separated in the PSA facilities.

On the other hand, as shown in the example considered in the introduction, even a significant difference in the binding energy of molecules of adsorbed gases by the surface of the adsorbent, the manifestation of which is the difference in the absolute value of the adsorption of gases by this adsorbent, does not provide an efficient separation of the gas mixture.

\section{RESULTS OF CALCULATIONS FOR THE MATHEMATICAL MODEL OF PSA}

According to the mathematical model described above, calculations were made of the PSA unit for obtaining oxygen. As adsorbents, $\mathrm{CaX}$, Oxysiv 5 and Oxysiv 7 zeolites have been chosen. The last two brands of zeolites have been developed in the Linde Air Products Division Laboratories specifically for use in PSA plants for oxygen production. Adsorption isotherms for these zeolites are taken: for $\mathrm{CaX}$ from the review [4], and for zeolites Oxysiv 5 and Oxysiv 7 from [15, 16, 17, 18, 19]. Figure 4 shows the isotherms of adsorption of nitrogen and oxygen for zeolites of the brands $\mathrm{CaX}$, Oxysiv 5 and Oxysiv 7.

The length of the adsorber in all calculations is taken equal to $0.5 \mathrm{~m}$, the period of the adsorbers switching is assumed equal to $120 \mathrm{~s}$, the characteristic grain size of the adsorbent is $1 \mathrm{~mm}$. At the plant inlet, a mixture of nitrogen and oxygen is supplied at an absolute pressure of 7 bars, and with an oxygen concentration of $21 \%$. All other parameters of the installation: the gas velocity in the adsorbers, the bulk weight of the adsorbent, the temperature of the adsorbent, and the like. adopted the same.

To simplify the analysis and interpretation of the calculation results, the mathematical model did not take into account the gas transfer between the adsorbers during their switching. If necessary, the gas transfer between the adsorbers can be easily taken into account, presetting the time of this operation.

Figure 5 shows the calculated graphs of the dependence of the oxygen concentration at the output from the PSA plant on the oxygen recovery ratio. 


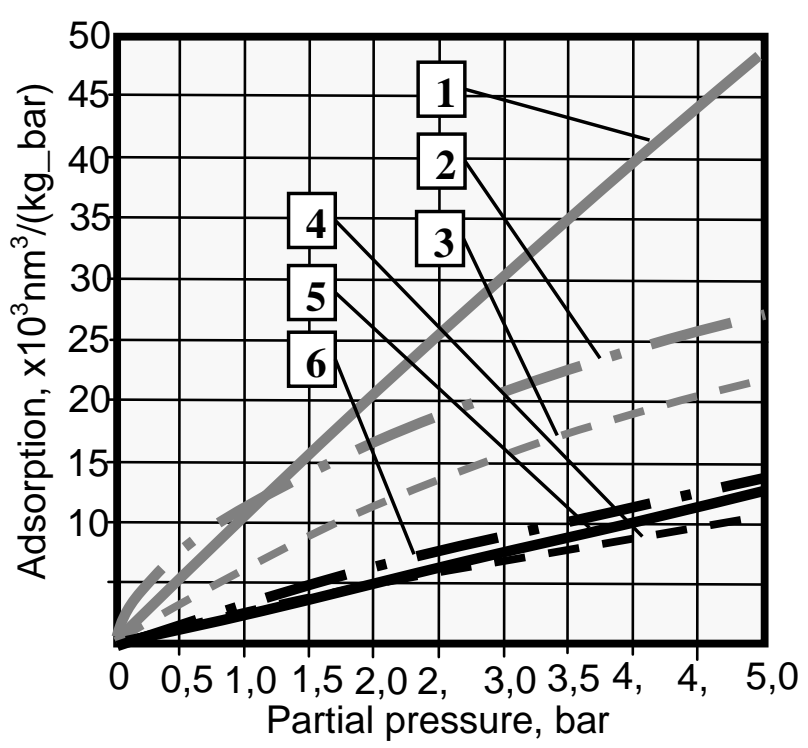

Figure 4. Adsorption of oxygen and nitrogen on zeolites brands $\mathrm{CaX}$, Oxysiv 5 and Oxysiv 7.

1 is nitrogen adsorption by zeolite $\mathrm{CaX}$; 2 is nitrogen adsorption by zeolite Oxysiv 7; 3 is nitrogen adsorption by zeolite Oxysiv 5; 4 is oxygen adsorption by zeolite Oxysiv 5; 5 is oxygen adsorption by zeolite Oxysiv 7; 6 is oxygen adsorption by zeolite $\mathrm{CaX}$

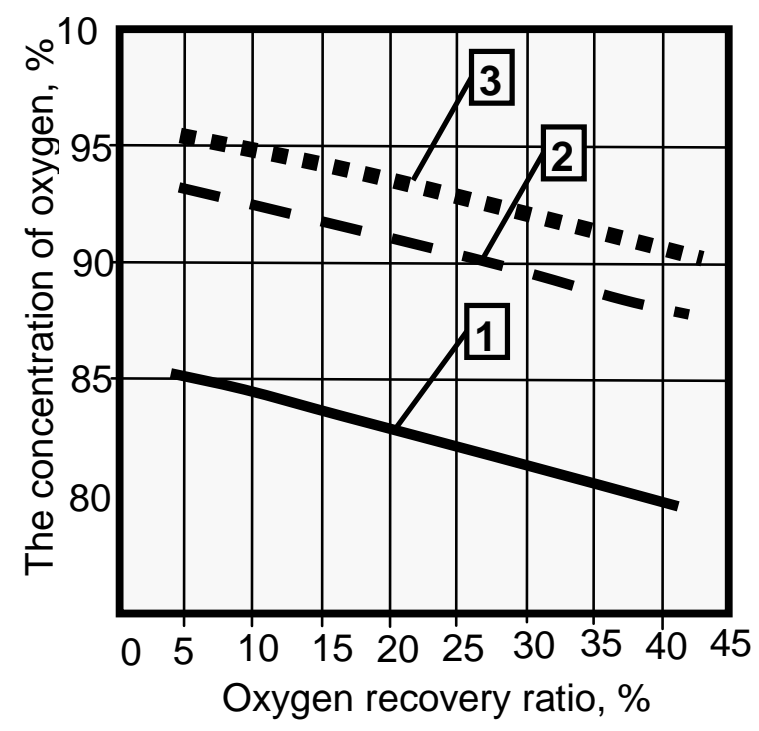

Figure 5. Calculated dependences of the oxygen concentration on the oxygen recovery ratio during the operation of the PSA on zeolites of the brands CaX, Oxysiv 5 and Oxysiv 7.

1is the CaX zeolite; 2 is the Oxysiv 5 zeolite; 3 is the Oxysiv 7 zeolite

The first thing to note is that the mathematical model makes it possible to explain the mechanisms by which oxygen concentrations greater than $90 \%$ are achieved with recovery ratio of more than $30 \%$. With the CaX zeolite, an oxygen concentration of $80 \%$ was obtained at a recovery ratio of $35 \%$. This significantly exceeds the result of the absorption of oxygen and nitrogen by a completely regenerated adsorbent, considered in the introduction.

It should be noted again that these results are achieved without taking into account the stage of equalizing the pressure in the adsorbers when they are switched. It is quite obvious that as a result of taking into account the gas bypass when switching adsorbers, the oxygen recovery ratio of PSA unit will increase.

This conclusion has experimental confirmation. The review [4] refers the results of the special study of PSA installations for producing oxygen, according to which the pressure equalization stage allows to reduce the energy consumption for obtaining the oxygen from $2.12 \mathrm{kWh} / \mathrm{m}^{3}$ to $0.51 \mathrm{kWh} / \mathrm{m}^{3}$. Therefore, taking into account the stage of pressure equalizing in the adsorbers, a calculated values of the oxygen concentration and oxygen recovery ratio will be even a higher, i.e. will be approximately the same as in industrial PSA installations.

Similar results are given in [20].

Calculations also show that adsorbents with a higher ratio of nitrogen and oxygen adsorption are not necessarily the best for PSA facilities. In the considered example, in case of the $\mathrm{CaX}$ zeolite, this ratio is higher than that of the Oxysiv 5 zeolite, however, the Oxysiv 5 zeolite gives significantly better oxygen production results than the CaX zeolite in the selected operating mode of the plant.

Pressure swing adsorption units, which are dynamic self-oscillating systems, have a complex behaviour. If for linear systems one can formulated statements similar to that: if one parameter is increases, then other parameter decrease or, on the contrary, increase, then for dynamical systems this is not so.

If you change any parameter in the adsorption phase, this will lead to a change in the parameters in the regeneration phase, and the change the parameters in the regeneration phase, in turn, affects the parameters of the adsorption phase. Therefore, in modelling the operation of PSA plants, it is necessary to consider entire working process as a single unit. The working process of a PSA installation can not be divided into separate phases, which can be analyzed separately.

This is fundamentally different from the existing practice of engineering calculations and design of technological processes, which is based on the dismemberment of complex processes into simpler parts that can be analyzed separately.

The wave approach to the consideration and calculation of a PSA plants is ideally suited for these purposes, since all phases of the plant operation are considered as a single whole, and as a result of the calculations, the parameters of the limiting cycles of a PSA unit are directly determined.

Exclusion from consideration of transients using the wave approach to the calculation of a PSA plants is a big advantage of this method, as this dramatically simplifies calculations.

\section{CONCLUSIONS}

A necessary condition for the efficient operation of the PSA unit is the adsorption of the separated components of the mixture at various active centres of the adsorbent 
surface. An external manifestation of this property of the adsorbent is the independence of adsorption of one component from saturation degree with other components of the mixture.

Even a significant difference in the binding energy of molecules of adsorbed gases with the adsorbent surface, the external manifestation of which is the difference in the absolute value of the adsorption of gases by this adsorbent, does not provide an effective separation of the gas mixture.

The wave approach to the analysis and calculation of the PSA processes makes it possible to find an analytical solution of a system of differential equations describing the operation of the adsorption apparatus. An analysis of the obtained solution indicates that this system of equations has several solutions, in the case of separation of a multicomponent mixture.

The mathematical model developed on the basis of the wave approach to the analysis and calculation of the PSA processes makes it possible to explain the mechanisms by which high oxygen concentrations are achieved with a recovery ratio of more than $40 \%$ in the best industrial designs of PSA plants.

\section{REFERENCES AND NOTES}

1. U.S. Patent 2,944,627 C.W. Scarstrom. Metod and apparatus for fractionating mixtures by adsorption, 1960.

2. Yang, R. T. Gas of separation by adsorption processes. Butterworths: Boston, 1987.

3. Ruthven, D.M., Farooq, S., Knaebel, K. S. Pressure Swing Adsorption. VCH Publishers Inc. New York, 1994. $189 \mathrm{p}$.

4. Glupanov V.G, Shmulyatsky Yu.I., Seregin Yu. A., and Brekhner S.. Obtaining oxygen and nitrogen by adsorption air separation. Overview information. Series XM-14. CINTICHEMNEFTEMASH. 1991, 45 p. (RUS)

5. Hayashi, S.; Kawai, M.; Kaneko, T. Dynamics of high purity oxygen PSA. Gas Separation \& Purification, 1996, 10, (1), p.19-23.

6. Jee, J.G.; Lee, J.S.; Lee, C.H. Air separation by a smallscale two-bed medical $\mathrm{O}_{2}$ Pressure Swing Adsorption. Industrial \& Engineering Chemical Research, 2001, (40), p.3647-3658.

7. Ruthven, D.M.; Xu, Z. Diffusion of Oxygen and Nitrogen in 5A Zeolite Crystals and Commercial 5A Pellets. Chemical Engineering Science, 1993, 48, (18), p.3307-3312.

8. Sherman, J.D., Synthetic zeolites and other microporous oxide molecular sieves. Proceedings of the National Academy of Sciences of the United States of America, 1999, 96, (7), p.3471-3478.
9. Cruz, P., Santos, J.C., Magalhães, F.D., Mendes, A. Cyclic adsorption. Processes: Analysis strategy and optimization procedure. Chemical Engineering Science, 2003, 58, (14), p.3143-3158.

10. Santos, J.C., Portugal, A. F., Magalhães, F.D., Mendes, A. Simulation and optimization of small oxygen pressure swing adsorption units. Industrial \& Engineering Chemistry Research, 2004, 43, (26), p.8328-8338.

11. Teague, K.G., Jr., Edgar, T.F. Predictive dynamic model of a small pressure swing adsorption. Industrial \& Engineering Chemical Research, 1999, 38, (10), p.37613775 .

12. Farooq, S.; Ruthven, D.M.; Boniface, H.A., NumericalSimulation of a Pressure Swing Adsorption Oxygen Unit. Chemical Engineering Science, 1989, 44, (12), p.28092816.

13. Kravchenko M.B. Wave adsorption. Analytical description and analysis of processes. Technical gases. 2011. - №5. - p.49-59. (RUS)

14. Kravchenko M.B. Wave adsorption. Influence of grain size of adsorbent on short-cycle adsorption processes. Refrigeration engineering and technology. -2012 . - No. 3. - p.63-74.

15. João Carlos Godinho de Faria dos Santos. Study of New Adsorbents and Operation Cycles for Medical PSA Units. The dissertation is presented for the degree of Doctor of Chemical Engineering by Universidade do Porto. 2005. $224 \mathrm{p}$.

16. Do, D.D. Adsorption Analysis: Equlibria and Kinetics. Imperial College Press: London, 1998.

17. Dreisbach, F.; Lösch, H.W.; Harting, P., Highest Pressure Adsorption Equilibria Data: Measurement with Magnetic Suspension Balance and Analysis with a New Adsorbent / Adsorbate-volume. Adsorption, 2002, 8, (2), p.95-109.

18. Hutson, N.D.; Zajic, S.C.; Rege, S.U.; Yang, R.T. Air Separation by Pressure Swing Adsorption Using Superior Adsorbents. University of Michigan: Ann Arbor, 2001.

19. Hutson, N.D.; Zajic, S.C.; Yang, R.T. Influence of residual water on the adsorption of atmospheric gases in Li$\mathrm{X}$ zeolite: Experiment and simulation. Industrial \& Engineering Chemistry Research, 2000, 39, (6), p.17751780 .

20. Chou, C.T.; Huang, W.C. Incorporation of a Valve Equation into the Simulation of a Pressure Swing Adsorption Process. Chemical Engineering Science, 1994, $49,(1)$, p.75-84.

Received 05 February 2018 Approved 20 March 2018 Available in Internet 30 June 2018 